\title{
Optimizing Environmental Conditions for Mass Application of Mechano-dwarfing Stimuli to Arabidopsis
}

\author{
Jill A. Montgomery, Ray A. Bressan, and Cary A. Mitchell \\ Department of Horticulture and Landscape Architecture, Purdue University, 625 Agriculture Mall Drive, \\ West Lafayette, IN 47907-2010
}

\begin{abstract}
AdDITIONAL INDEX WORDS. brushing, daylength, hypocotyl, impedance, mechanical stress, photomorphogenesis, PPF, temperature

Aвstract. Obtaining uniform mechano-dwarfing of Arabidopsis thaliana (L.) Heynh. seedlings within dense plantings is problematic. Alternative forms of mechano-stimulation were applied to seedlings in effort to obtain uniform growth reduction compared with undisturbed controls in both greenhouse and controlled growth environments. Arabidopsis grown under low photosynthetic photon flux (PPF) artificial light grew upright with limited leaf expansion, which enhanced mechano-responsiveness compared to that of rosette-growing plants under filtered sunlight or high PPF artificial light. Hypocotyls of seedlings grown at PPFs $>60 \mu \mathrm{mol} \cdot \mathrm{m}^{-2} \cdot \mathrm{s}^{-1}$ elongated less and had $6 \%$ less sensitivity to mechanical stress than seedlings grown at PPFs $<60 \mu \mathrm{mol} \cdot \mathrm{m}^{-2} \cdot \mathrm{s}^{-1}$. Fluorescent lamps alone (F) or fluorescent plus incandescent $(\mathrm{F}+\mathrm{I})$ lamps were compared for seedling responses to mechanical stress. Under $F$ lighting, hypocotyl elongation was reduced $25 \%$ to $\mathbf{4 0 \%}$ by twice-daily brush or plate treatments, and brushed seedlings exhibited more growth reduction than did plate treatments. Seedlings grown under F+I lamps exhibited similar stress-induced growth reduction compared to seedlings grown under $\mathrm{F}$ only, but stressed $\mathrm{F}+\mathrm{I}$ seedlings lodged to a greater extent due to excessive hypocotyl elongation. Temperature-response studies using standardized F-only lighting indicated increased hypocotyl elongation but decreased leaf expansion, and decreased mechano-responsivity to brushing over the temperature range from 20 to $28{ }^{\circ} \mathrm{C}$. Daylength studies indicated similar degrees of mechano-inhibition of hypocotyl elongation over the daylength range of 12, 16, 20, and 24 hours, whereas fresh weight of stressed seedling shoots declined compared to controls. A combination of environmental growth parameters that give repeatable, visual mechanical dwarfing of Arabidopsis include low-PPF fluorescent lighting from 55 to $60 \mu \mathrm{mol} \cdot \mathrm{m}^{-2} \cdot \mathrm{s}^{-1}$, ambient temperatures from 22 to $25^{\circ} \mathrm{C}$, and twice-daily brush treatments.
\end{abstract}

Mechanical stresses are common among plants growing in nature. Mechanical stress causes physiological responses that can reduce height, leaf area, and biomass compared to undisturbed controls (Jaffe, 1973; Mitchell et al., 1975). The resulting growthinhibitory effects have inspired the intentional application of stress to seedlings growing in greenhouses to adapt them for outdoor transplant (Latimer, 1991). Various forms of mechanical stress have been tested for their hardening effects on horticultural crops. Brushing (Pontinen and Voipoi, 1992) or static impedance (Garner and Bjorkman, 1997) lead to growth reduction with no visible damage. Few studies have been done to optimize environmental growth parameters for mechano-sensitivity (Jaffe, 1973; Heuchert and Mitchell, 1983; Jones and Mitchell, 1992).

This project identifies a set of conditions that permit uniform response of Arabidopsis seedlings en masse to mechanical stress and is part of a broader effort to identify T-DNA insertional mutant phenotypes unresponsive to mechano-stimuli and genes mediating the process.

Individual Arabidopsis plants receiving daily, noninjurious contact stress exhibit growth reductions during bolting (Braam and Davis, 1990). However, to develop an effective mass mechano-dwarfing screen, plants must be small and vegetative to avoid competing physical interactions that occur among closely spaced, bolting plants. The present article describes the systematic approach used to enhance and validate the uniform mechano-dwarfing re-

Received for publication 11 June 2003. Accepted for publication 1 Aug. 2003. The authors thank Polly Kaufmann and Judy Santini for consultation on experimental design and statistical analysis. They also acknowledge the assistance of Adam Santone for experiment harvest and with computer applications throughout this work. Acknowledgement also is extended to Steve Weller and Robert Joly for careful review of this article. sponse of wild-type Arabidopsis that could be developed into a mutant screen.

\section{Methods and Materials}

Initial experiments were conducted in greenhouse $(\mathrm{GH})$ and growth-room (GR) environments, where brush and static-impedance stresses were applied and plant responses compared. Twentyfour flats each were planted with 400 Arabidopsis thaliana (L.) Heynh. seeds of the C-24 ecotype in commercial potting mix (Scotts Metromix 360) preleached with water. The flats were incubated for $4 \mathrm{~d}$ at $4{ }^{\circ} \mathrm{C}$ and then moved under intermittent mist (8-s spray every $10 \mathrm{~min}$ ) in a greenhouse. Seedlings emerged after $2 \mathrm{~d}$ under mist, and, after $4 \mathrm{~d}, 12$ flats were moved into a GH under $70 \%$ shade; the remaining 12 flats were transferred to the GR. Stress treatments were assigned randomly to flats, and each treatment (brush, plate, control) was replicated four times. Treatment was started after emergence of the first set of true leaves, $\approx 4 \mathrm{~d}$ after removal from the mist. Brush treatments were applied using a tri-layered, fringed, burlap brush. Each treatment consisted of 10 back-and-forth strokes applied twice daily $7 \mathrm{~h}$ apart beginning at $\approx 0900$ HR. Static-impedance treatments involved placing a 0.05$\mathrm{cm}$-thick perforated polycarbonate transparent plate on the flats for $12 \mathrm{~h}$ overnight. Photosynthetic photon flux (PPF) from highintensity discharge lamps was measured using a cosine-corrected quantum meter (LI-1776; LI-COR, Lincoln, Neb.) at bench level in the GR at 130 to $150 \mu \mathrm{mol} \cdot \mathrm{m}^{-2} \cdot \mathrm{s}^{-1}$, whereas PPF in the $\mathrm{GH}$ was uncontrolled. Temperatures were set at $22^{\circ} \mathrm{C}$ days $/ 20^{\circ} \mathrm{C}$ nights in the GR. Temperatures in the $\mathrm{GH}$ were controllable to within $10^{\circ} \mathrm{C}$ of ambient outside air during the summer. Flats were subirragated to avoid mechano-effects from overhead watering. Commercial 
Table 1. Effects of $6 \mathrm{~d}$ of mechanical stress treatments in two different growth environments on shoot dry weight and leaf area of Arabidopsis seedlings.

\begin{tabular}{|c|c|c|c|c|}
\hline \multirow[b]{2}{*}{ Treatment } & \multicolumn{2}{|c|}{ Greenhouse } & \multicolumn{2}{|c|}{ Growth room } \\
\hline & $\begin{array}{c}\text { Dry wt } \\
\text { (mg/plant) }\end{array}$ & $\begin{array}{c}\text { Leaf area } \\
\left(\mathrm{cm}^{2} / \text { plant }\right)\end{array}$ & $\begin{array}{c}\text { Dry wt } \\
\text { (mg/plant) }\end{array}$ & $\begin{array}{c}\text { Leaf area } \\
\left(\mathrm{cm}^{2} / \text { plant }\right)\end{array}$ \\
\hline Control & $3.39 \mathrm{a}^{\mathrm{z}}$ & $0.273 \mathrm{a}$ & $8.31 \mathrm{a}$ & $0.419 \mathrm{a}$ \\
\hline Brush & $3.74 \mathrm{a}$ & $0.293 \mathrm{a}$ & $9.40 \mathrm{a}$ & $0.429 \mathrm{a}$ \\
\hline Plate & $3.26 \mathrm{a}$ & $0.276 \mathrm{a}$ & $11.2 \mathrm{a}$ & $0.433 \mathrm{a}$ \\
\hline
\end{tabular}

2Data in columns followed by the same letter are not significantly different at $P=0.05$ according to Tukey's $\omega$-procedure.

micronutrient and NPK-enriched water was given to each flat every third watering. Plants received 14 consecutive days of mechanicalstress treatments and were 28-d-old from seeding at harvest.

Total leaf area per flat was determined from overhead digital photographs. The images were imported into Photoshop and converted into grayscale. Black pixel counts of the leaves were compared to those for a standard area. Average leaf area per plant was calculated based on pixel counts and number of plants per flat. Growth also was expressed as average shoot fresh and dry weights per plant. Shoot fresh weight of total seedlings per flat was taken immediately after harvest, and dry weights were measured after the biomass was dried for $24 \mathrm{~h}$ in a $65^{\circ} \mathrm{C}$ forced-air drying oven.

Subsequent experiments conducted in the laboratory used a growth medium that improved control of nutritional and waterstatus parameters. Rockwool (Grodan) slabs $(28 \times 20 \times 4.5 \mathrm{~cm})$ were placed in aluminum trays and each slab was hydrated with $1500 \mathrm{~mL}$ of $0.25 \times$ Hoagland's no. 1 nutrient solution ( $\mathrm{pH}$ 5.5). Because high calcium concentrations have been related to decreased mechano-sensitivity (Myers and Mitchell, 1993), calcium concentration in the nutrient solution was reduced to $0.5 \mathrm{~mm}$. Seed weights equivalent to 400 seeds were mixed with $3 \mathrm{~g}$ acid-washed sand and sown onto each wetted slab using a salt shaker. Trays were covered with saran wrap and stratified for $4 \mathrm{~d}$ at $4{ }^{\circ} \mathrm{C}$. They were then moved under light banks, where the saran wrap was replaced with a propped transparent plastic dome. Lamp height was adjusted so that PPF was $55 \mu \mathrm{mol} \cdot \mathrm{m}^{-2} \cdot \mathrm{s}^{-1}$ under the domes. Treatments were started 3 d after removal from the cooler. Brush treatments consisted of twice-daily applications (10 back-and-forth strokes), and static impedance was applied for 1 hour twice daily (0900 to $1000 \mathrm{HR}$, 1600 to $1700 \mathrm{HR})$ by placing one plate $\left(0.33 \mathrm{~g} \cdot \mathrm{cm}^{-2}\right)$ on each flat. A 16-h daylength was used unless otherwise indicated. Treatments were given for $6 \mathrm{~d}$ before harvest. Harvested seedlings were 13d-old from planting.

An experiment was conducted to identify the PPF needed for adequate hypocotyl elongation as well as for best mechano-sensitivity. Four light banks were used, each containing two 32-W fluorescent lamps. Four flats were placed under each bank at varying distances from the lamps to obtain four different PPF levels (40, 50,70 , and $80 \mu \mathrm{mol} \cdot \mathrm{m}^{-2} \cdot \mathrm{s}^{-1}$ ).

An experiment was conducted to compare plant response to mechanical stress under either fluorescent plus incandescent lamps $(\mathrm{F}+\mathrm{I})$ or fluorescent lamps alone $(\mathrm{F})$. Each lamp bank was equipped with two 32-W fluorescent lamps, plus three 15-W incandescent bulbs spaced $30.5 \mathrm{~cm}$ apart along the $122-\mathrm{cm}$ bank (1.44:1 ratio of fluorescent-to-incandescent wattage). Both lighting regimes were adjusted to maintain a total PPF of $55 \mu \mathrm{mol} \cdot \mathrm{m}^{-2} \cdot \mathrm{s}^{-1}$.

A study was conducted to find the temperature range optimal for mechano-sensitivity. Four growth chambers (Conviron models E8 and E15) were set at different day/night temperature regimes $\left(22 / 20,24 / 22,26 / 24,28 / 26^{\circ} \mathrm{C}\right)$. Each chamber contained brush and control treatment trays replicated four times each. Daylength was set at $16 \mathrm{~h}$. Average daily temperatures (ADTs) of the treatments were $21.3,23.3,25.3$, and $27.3^{\circ} \mathrm{C}$, respectively.

Alaboratory experiment was conducted to distinguish effects of varying daylength on mechano-stress responsiveness. Fluorescent lamp banks were maintained at daylengths of 12, 16, 20, or $24 \mathrm{~h}$.

Growth was measured as hypocotyl length and leaf area. Hypocotyl length was measured for a random subset of 25 seedlings from each flat. Leaf area was determined using the photographic protocol described. Statistical analysis of data included analysis of variance (ANOVA) and mean-separation tests (Tukey's $\omega$-procedure) (Steele and Torrie, 1960) at the 95\% confidence level.
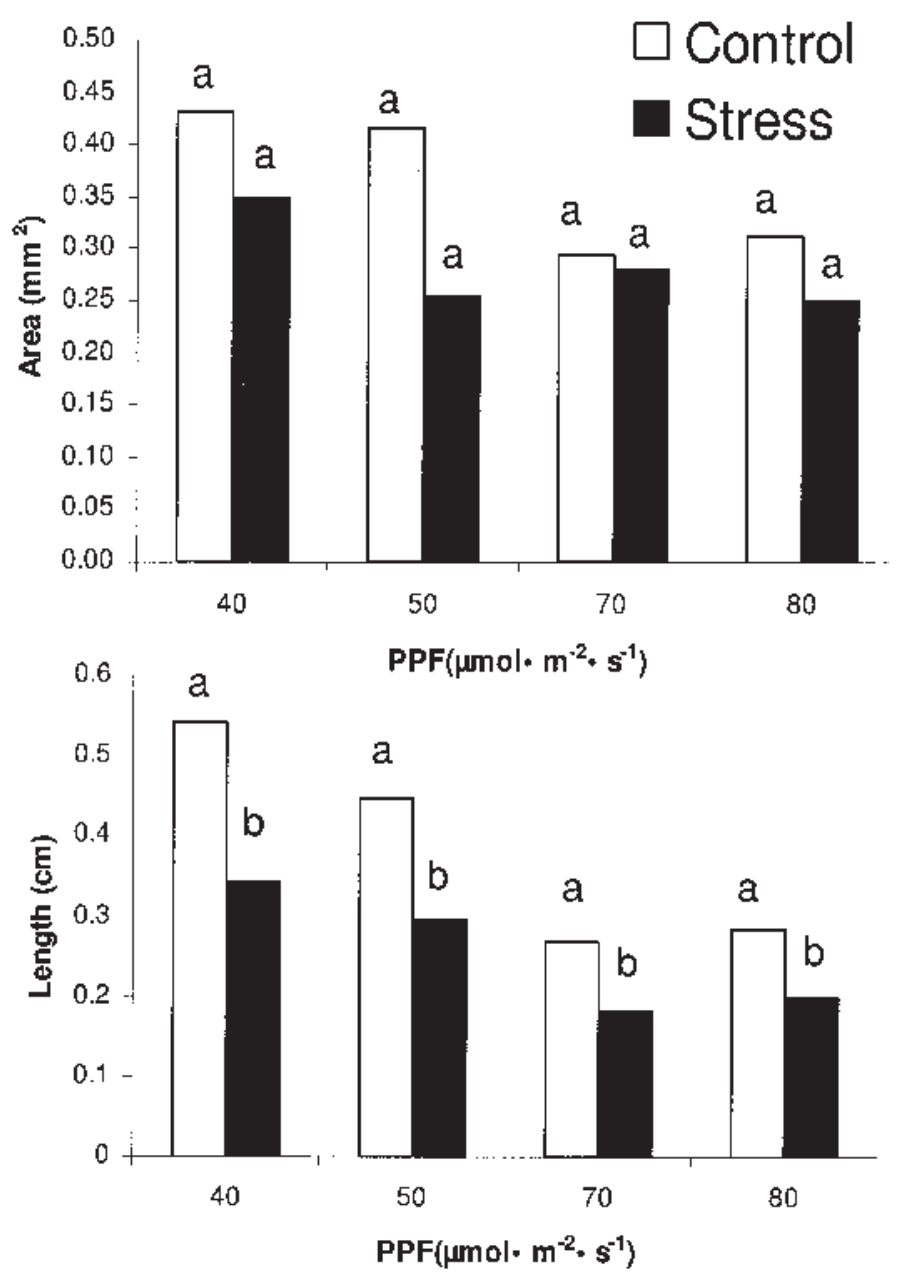

Fig. 1. Effects of $6 \mathrm{~d}$ of brushing treatment on leaf area (top) and hypocotyl length (bottom) under differing PPF levels. Different letters indicate significant differences at $P=0.05$, Tukey's $\omega$-procedure. 
Table 2. Effects of transparent domes on photosynthetic photon flux (PPF), phytochrome photostationary state (PPS) and hypocotyl length of Arabidopsis seedlings after $6 \mathrm{~d}$ of brush treatment.

\begin{tabular}{lcccc}
\hline & PPF & & \multicolumn{2}{c}{ Hypocotyl length } \\
\cline { 2 - 4 } Treatment & $\left(\mu \mathrm{mol} \cdot \mathrm{m}^{-2} \cdot \mathrm{s}^{-1}\right)$ & PPS & Control $(\mathrm{mm})$ & Stress $(\mathrm{mm})$ \\
\hline Domes & 54.0 & 0.8387 & 0.186 & $4.10 \pm 0.177$ \\
No Domes & 58.5 & 0.8366 & $3.56 \pm 0.057$ & $2.57 \pm 0.180$ \\
\hline
\end{tabular}

\section{Results}

Stressed seedlings exhibited no consistent growth reductions compared to controls after $10 \mathrm{~d}$ of twice-daily treatments when grown in the GH or GR (Table 1). Plants in the GR grew twice as large as those in the GH, but dry weight of stressed plants did not differ significantly from that of controls in either environment. Leaf area of brushed plants also was not reduced compared to controls, but the leaf area of plated seedlings undergoing static impedance treatments actually increased. Static-impedance plates prevented upward growth of seedlings during treatment, but stimulated lateral leaf expansion, even though plates were in place for only $2 \mathrm{~h} \cdot \mathrm{d}^{-1}$.

Seedlings grown using an inert growth medium and artificial low PPF assumed an upright, caulescent growth habit compared to the acaulescent, rosette growth habit of seedlings grown under higher PPF in the GH or GR environments. Brush treatments were applied to trays of seedlings grown under different PPFs (40, 50, 70 , or $80 \mu \mathrm{mol} \cdot \mathrm{m}^{-2} \cdot \mathrm{s}^{-1}$ ). Leaf area of brushed seedling was not significantly affected by stress, but there was a strong trend toward reduced leaf expansion compared to controls (Fig. 1). Hypocotyl length of brushed seedlings was significantly shorter than that of controls after $6 \mathrm{~d}$ of treatment. Low PPF ( 40 or $50 \mu \mathrm{mol} \cdot \mathrm{m}^{-2} \cdot \mathrm{s}^{-1}$ ) per se increased hypocotyl growth $42 \%$ compared to that under

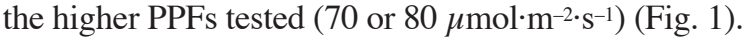
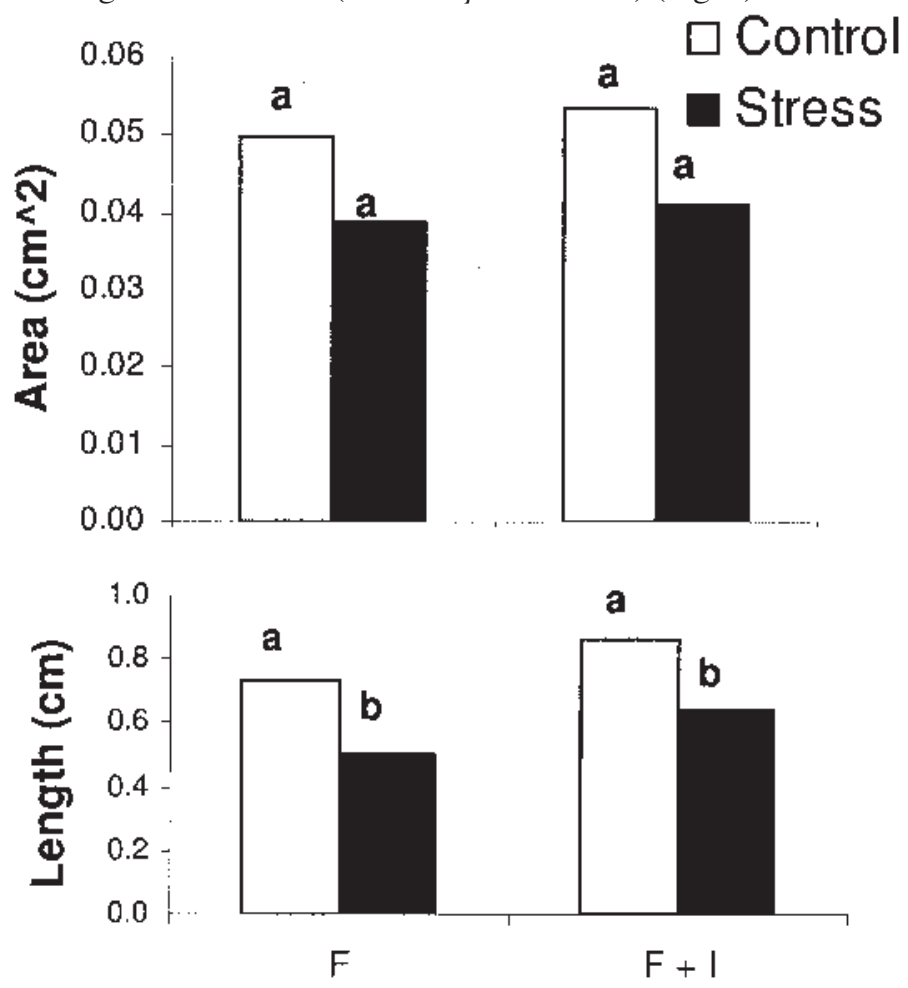

Fig. 2. Effects of $6 \mathrm{~d}$ of brushing treatment on leaf area (top) and hypocotyl length (bottom) under fluorescent $(\mathrm{F})$ or fluorescent plus incandescent $(\mathrm{F}+\mathrm{I})$ lighting regimes. Different letters indicate significant differences at $P=0.05$, Tukey's $\omega$-procedure.
Seedling growth under low-PPF artificial light was compared with and without plastic, transparent domes covering the flats. Use of domes reduced total PPF only $7 \%$ but maintained a constant phytochrome photostationary state (PPS). PPS is the equilibrium achieved between the red-light-absorbing phytochrome $(\operatorname{Pr})$ and the far-red-absorbing form (Pfr), and was measured with a spectroradiometer (LI-C1800). Hypocotyl elongation of stressed seedlings was reduced $39 \%$ compared to controls when domes were used. When domes were not used, only a $28 \%$ growth reduction occurred (Table 2).

Two mechanical-stress treatments (brush or plates) were compared under two light-quality regimes (F vs. F+I) (Figs. 2 and 3). No significant differences in leaf area to mechano-response occurred for brushed vs. control seedlings (Fig. 2). The most obvious, visual response to stress was reduced hypocotyl elongation. Hypocotyl elongation was reduced $39.4 \%$ by brushing plants grown under $\mathrm{F}$ lights. Under $\mathrm{F}+\mathrm{I}$ lights, hypocotyl elongation was reduced $34.5 \%$ by stress compared to controls. Overall, F+I seedlings grew taller but lodged more easily when stressed. The hypocotyls of F-lighted seedlings grew thicker and were less prone to lodging
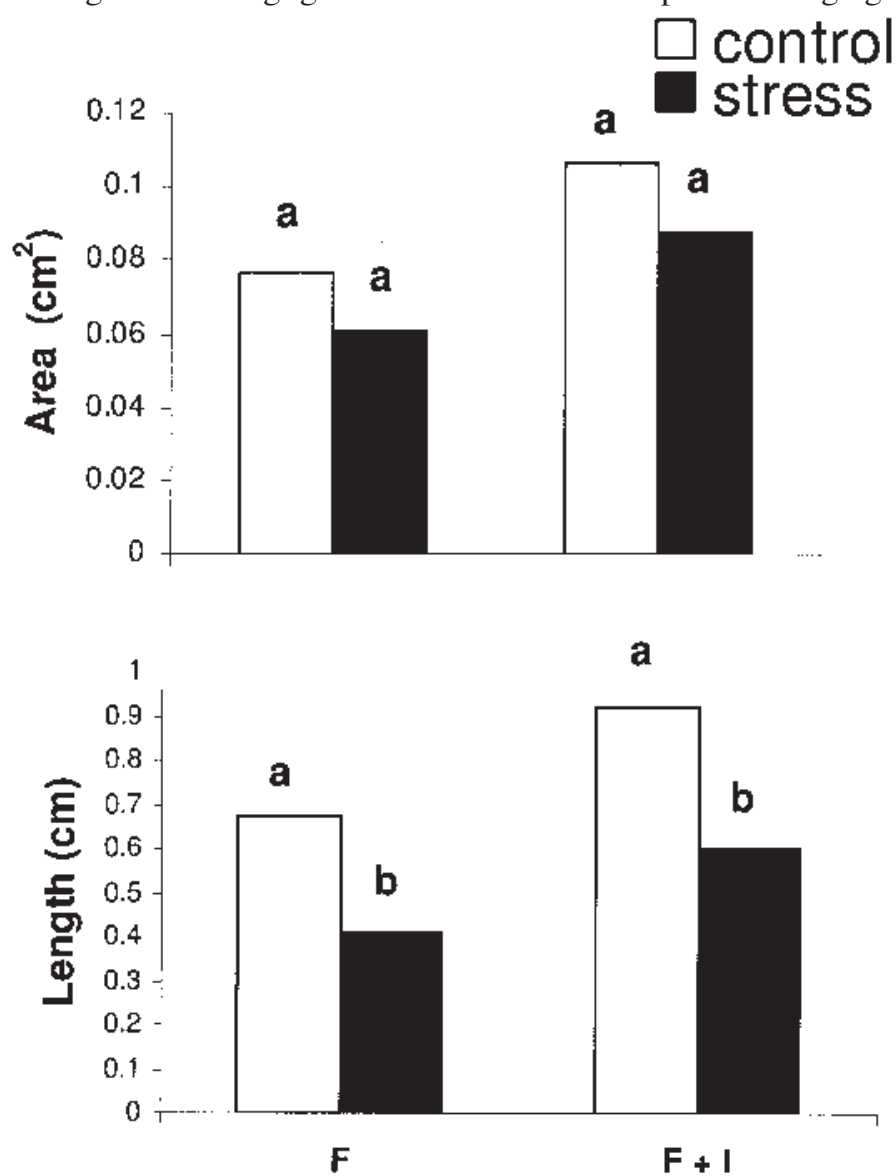

Fig. 3. Effects of twice-daily 1-h impedance plate treatments on leaf area (top) and hypocotyl length (bottom) under fluorescent $(F)$ or fluorescent plus incandescent $(\mathrm{F}+\mathrm{I})$ lighting regimes. Different letters indicate differences at $P=0.05$, Tukey's $\omega$-procedure. 

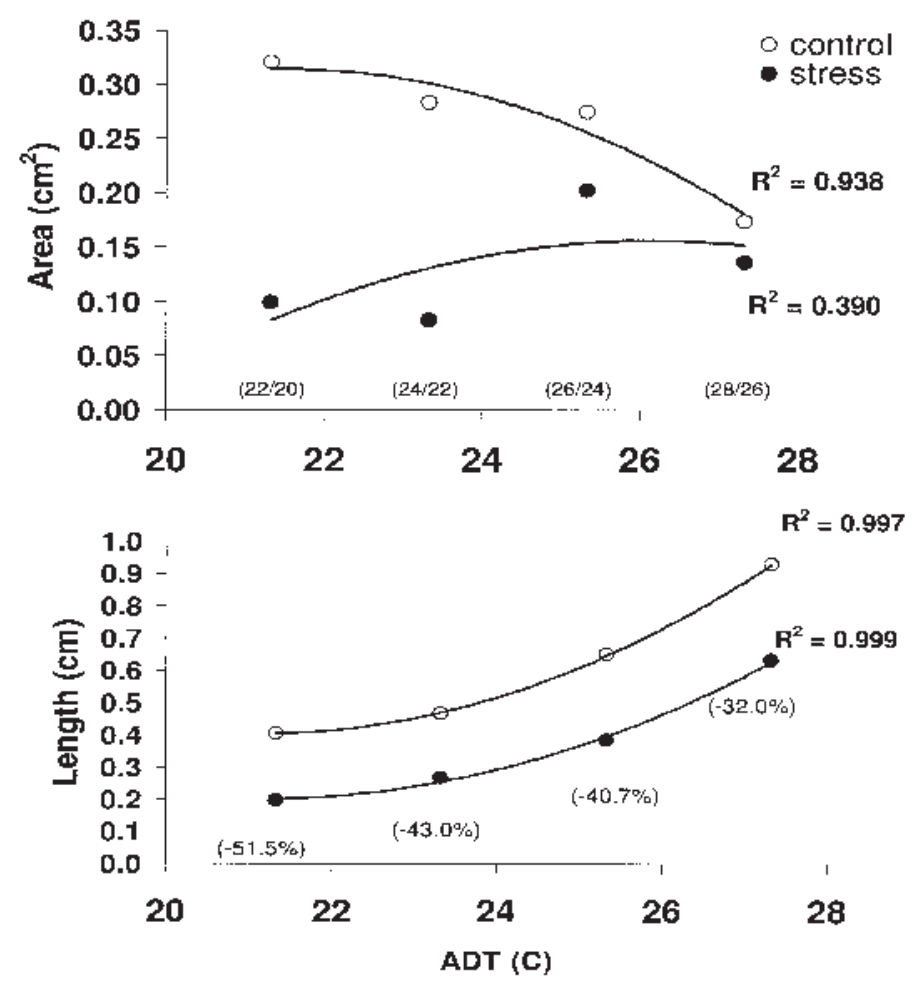

must be reliable, repeatable, and, most important, visual. Arabidopsis seedlings grown in the GH/GR, while showing high sensitivity to mechanical stress at the bolting stage (Fig. 6), were far too large at that stage of development, growing together and causing many physical interactions among plants. From the interactions between seedlings and the need to select variant individuals from the flats, screened plants would have to remain more widely spaced or be smaller at the time of screening. In the GH/GR environments, PPF was found to be supraoptimal at levels around $150 \mu \mathrm{mol} \cdot \mathrm{m}^{-2} \cdot \mathrm{s}^{-1}$ and higher. Unfavorable root-zone environments (variable water status, high $\mathrm{pH}$, and salt accumulation) along with uncontrolled temperatures also reduced uniformity of response.

Plate treatments increased lateral leaf expansion, possibly due to localized humidification and improved water status, although those conditions lasted only 2 out of every $24 \mathrm{~h}$.

The typical rosette growth habit of Arabidopsis protects the recessed shoot apex from receiving mechanical stimulation. It was concluded that upright stem growth is a practical necessity for mechano-dwarfing of vegetative Arabidopsis.

Under laboratory conditions, the reasons for upright hypocotyl growth and mechanoresponsivity were suspected to be related to low total irradiance, dosage of blue light, and/or red/far-red ratio of the light source. Use of low PPF (40 to $50 \mu \mathrm{mol} \cdot \mathrm{m}^{-2} \cdot \mathrm{s}^{-1}$ ) permitted significant mechano-dwarfing because of the

Fig. 4. Effects of different day/night temperature regimes and the resultant average daily temperature (ADT) on average plant hypocotyl length (top) and average leaf area per plant (bottom), as well as on plant responsivity to daily brush treatments. Second-order regression equations are as follows:

Length/control: $y=0.054 \times 2-0.098 x+0.45$

Length/stress: $y=0.044 \times 2-0.079 x+0.24$

Leaf area/control: $y=-0.016 \times 2+0.033 x+0.30$

Leaf area/stress: $y=-0.013 \times 2+0.086 x+0.0094$

when stressed. Leaf area of plated seedlings also was not reduced significantly (Fig. 3). A 31.5\% reduction in hypocotyl elongation was measured under F lights, and a $26.0 \%$ reduction was measured for $\mathrm{F}+\mathrm{I}$ plated plants. The seedlings of plate treatments required a longer reorientation period once the plates were removed compared to brush treatments.

Hypocotyl elongation increased concomitant with increasing average daily temperature (ADT), but sensitivity to brush treatments declined (Fig. 4). On the other hand, leaf area expansion declined with increasing ADT.

Overall, stress sensitivity was constant over the range of daylengths tested. As both daylength and daily PPF $\left(\mathrm{mol} \cdot \mathrm{m}^{-2} \cdot \mathrm{d}^{-1}\right)$ increased at constant, instantaneous PPF $\left(\mu \mathrm{mol} \cdot \mathrm{m}^{-2} \cdot \mathrm{s}^{-1}\right)$, shoot fresh weight also increased, but sensitivity to brushing declined from a $37.6 \%$ reduction in fresh weight with a 12 -h daylength to a $9.2 \%$ reduction with a 24-h daylength (Fig. 5).

\section{Discussion}

A successful mass mechano-dwarfing screen for Arabidopsis drastic increase in hypocotyl elongation of controls that does not occur at higher PPF (70 to $\left.80 \mu \mathrm{mol} \cdot \mathrm{m}^{-2} \cdot \mathrm{s}^{-1}\right)$ (Fig. 1). While low PPF under either F+I (Fig. 7) or F-only (Fig. 8) lighting treatments both promoted hypocotyl elongation, it was found that $\mathrm{F}$ lighting alone at low PPF was the most effective lighting regimen. In Experiments where total PPF was varied from 40 to $80 \mu \mathrm{mol} \cdot \mathrm{m}^{-2} \cdot \mathrm{s}^{-1}$ (Fig. 1$)$, the changes in hypocotyl elongation could be attributed to blue-light dosages sensed by cryptochrome (Ahmad and Cashmore 1993), but in experiments testing mechano-sensitivity between $\mathrm{F}$ and $\mathrm{F}+\mathrm{I}$ lighting the blue light dosage did not change, indicating that the far-red output of incandescent lamps also had a significant, opposite effect on hypocotyl elongation.

Preliminary studies using transparent plastic domes loosely covering seeded rockwool slabs induced superior growth double that of seedlings grown without domes. The dome effect also promoted sensitivity to mechanical stress (Table 2). The domes retarded water loss from the growth system presumably by creating a localized microclimate with increased humidification. Domes also protect seedlings from uncontrolled room air currents that otherwise might harden off seedlings to mechano-treatments. Phytochrome photostationary state was measured under fluorescent light with and without domes, and the ratios of $\left[\mathrm{P}_{\mathrm{fr}}\right]$ to total $[\mathrm{P}]$ at photo-equilibrium were not different (Sager et al. 1988). Spectroradiometer scans across the entire visible range of wavelengths suggested that domes caused no selective wavelength filtering, and decreased total PPF only $7 \%$.

In previous studies, Jaffe (1976) and Heuchert and Mitchell (1983) found that mechanical-stress sensitivity is reduced if plants 

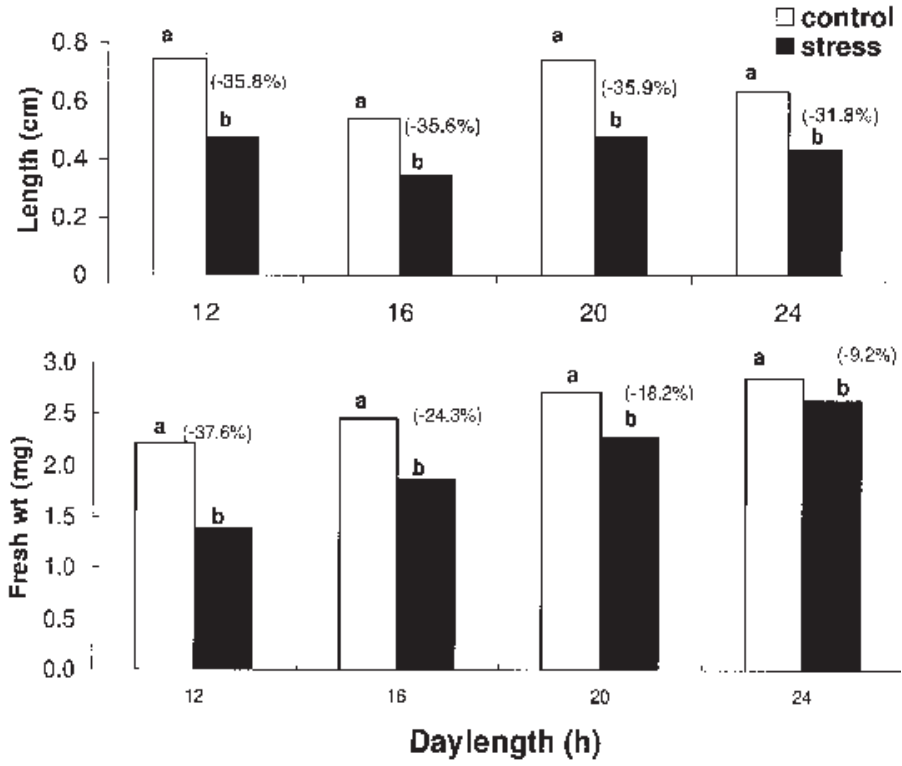

a $\quad 9.2 \%\}$

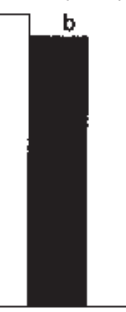

b

24

are grown outside their optimal temperature range. Plants grown at the low end of the temperature range $\left(22 / 20^{\circ} \mathrm{C}\right)$ in this study had the most sensitivity to mechanical stress but also grew the slowest (Fig. 4). Since one goal is to screen thousands of mutant lines as quickly as possible, a $24 / 22{ }^{\circ} \mathrm{C}$ day/night temperature regime was selected as an effective compromise temperature regime for enhancement of Arabidopsis seedling growth while still giving adequate stress responses.

Since similar mechano-induced hypocotyl growth reductions occurred at all daylengths tested, a 16-h daylength was selected because it gave reasonable growth within $6 \mathrm{~d}$ of growth and treatment. Longer daylengths were associated with higher daily dosages of photosynthetically active radiation. Growth measurements based on shoot fresh and dry weight indicated less sensitivity to mechanical stress at higher daily PPF, even though plants were grown at an instantaneous PPF that was conducive to good mechanical response. Use of a 16-h daylength was an effective compromise leading to uniform mechano-dwarfing.

Conditions selected for an optimum visual screen of Arabidopsis mechanical-stress

Fig. 5. Effects of different daylengths at a constant PPF of $55 \mu \mathrm{mol} \cdot \mathrm{m}^{-2} \cdot \mathrm{s}^{-1}$ on hypocotyl length (top) and shoot fresh weight per plant (bottom), as well as on responsiveness to daily brush treatments. Bar pairs with different letters were significantly different from each other at $P=0.05$, Tukey's $\omega$-procedure.

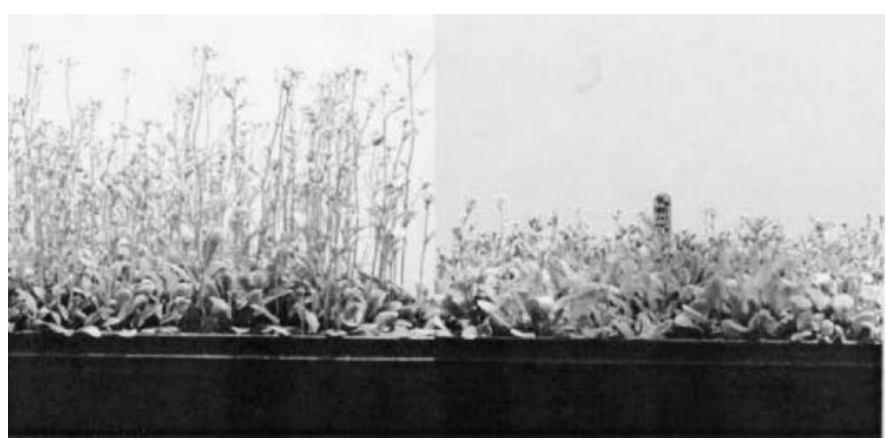

Fig. 6. Arabidopsis at the bolting stage grown in the greenhouse. Control (left) and stressed (right) seedlings after $7 \mathrm{~d}$ of plate treatment.

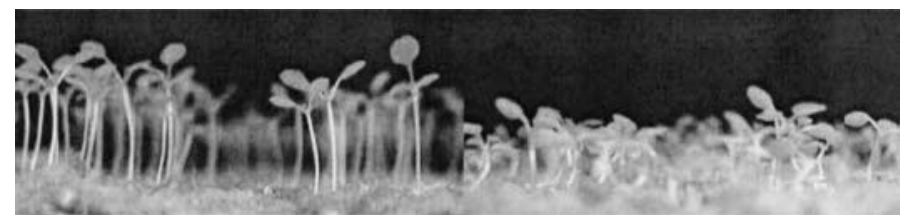

Fig. 7. Control (left) and stressed (right) Arabidopsis seedlings grown under fluorescent-plus-incandescent lamps after $8 \mathrm{~d}$ of twice daily-brush treatments.

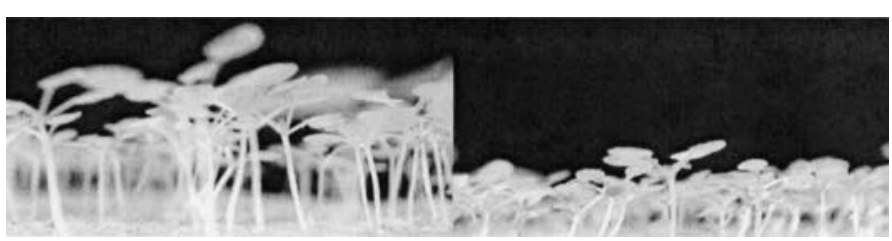

Fig. 8. Control (left) and stressed (right) Arabidopsis seedlings grown under fluorescent lamps only after $6 \mathrm{~d}$ of twice-daily brush treatments.

response include a combination of fluorescent lights at low PPF (50 to $60 \mu \mathrm{mol} \cdot \mathrm{m}^{-2} \cdot \mathrm{s}^{-1}$ ) for $16 \mathrm{~h}$, ambient temperatures at $24 / 22$ ${ }^{\circ} \mathrm{C}$, twice-daily brushing treatments, use of protective transparent domes, and a uniform and controlled nutrient solution and growth medium.

\section{Literature Cited}

Ahmad, M. and A. Cashmore. 1993. HY4 gene of A. thaliana encodes a protein with characteristics of a blue-light photoreceptor. Nature 336:162-166.

Braam, J. and R. Davis. 1990. Rain-, wind-, and touch-induced expression of calmodulin and calmodulin-related genes in Arabidopsis. Cell 60:357-364.

Garner, L.C. and T. Bjorkman. 1997. Using impedance for mechanical conditioning of tomato transplants to control excessive stem elongation. HortScience 32(2): 227-229.

Heuchert, J. and C. Mitchell. 1983. Inhibition of shoot growth in greenhouse-grown tomato by periodic gyratory shaking. J. Amer. Soc. Hort. Sci. 108:795-800.

Jaffe, M. 1973. Thigmomorphogenesis: The response of plant growth and development to mechanical stimulation. Planta 114:143-157.

Jaffe, M. 1976. Thigmomorphogenesis: a detailed characterization of the response of beans to mechanical stimulation. Z. Pflanzenphysiol. 77S:437-453.

Jones,R. and C. Mitchell. 1992. Effects of physical agitation on yield of greenhousegrown soybean. Crop Sci. 32:404-408.

Jones, R., L.Coe, L. Montgomery, and C. Mitchell. 1990. Seismic stress responses of soybean to different photosynthetic photon flux. Ann. Bot. 66:617-622.

Latimer, J. 1991. Mechanical conditioning for control of growth and quality of vegetable transplants. Hortscience 26:1456-1461.

Mitchell, C.A., C.J. Severson, J.A. Wott, and P.A. Hammer. 1975. Seismomorphogenic regulation of plant growth. HortScience 100:161-165.

Myers, P. and C. Mitchell. 1993. Growth and turgor of dark-grown soybean seedlings following mechanical stress. Bul. Amer. Soc. Grav. Space Biol. 7:94.

Pontinen, V. and I. Voipoi. 1992. Different methods of mechanical stress in controlling the growth of lettuce and cauliflower seedlings. Acta. Agr. Scand. Sect B, Soil and Plant Sci. 42:246-250.

Sager, J., W. Smith, J. Edwards, and K. Cyr. 1988. Photosynthetic efficiency and photochrome photoequilibria determination using spectral data. Amer. Soc. Agr. Eng. 31(6): 1882-1889.

Steel, R. and J. Torrie. 1960. Principles and procedures of statistics. McGraw-Hill Book Co. 